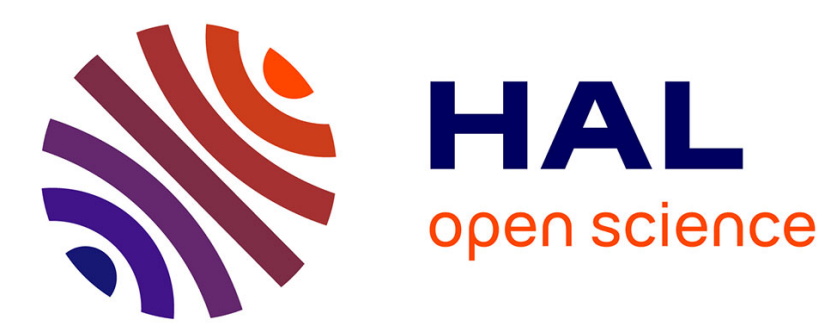

\title{
Does Implicit Voting Matter? Coalitional Bargaining in the EU Legislative Process
}

\author{
Cesar Garcia Perez de Leon
}

\section{To cite this version:}

Cesar Garcia Perez de Leon. Does Implicit Voting Matter? Coalitional Bargaining in the EU Legislative Process. European Union Politics, 2012, 13 (4), pp.513-534. 10.1177/1465116512453883 . hal-01024684

\section{HAL Id: hal-01024684 \\ https://hal-sciencespo.archives-ouvertes.fr/hal-01024684}

Submitted on 16 Jul 2014

HAL is a multi-disciplinary open access archive for the deposit and dissemination of scientific research documents, whether they are published or not. The documents may come from teaching and research institutions in France or abroad, or from public or private research centers.
L'archive ouverte pluridisciplinaire HAL, est destinée au dépôt et à la diffusion de documents scientifiques de niveau recherche, publiés ou non, émanant des établissements d'enseignement et de recherche français ou étrangers, des laboratoires publics ou privés. 


\section{European Union Politics \\ http://eup.sagepub.com/}

\section{Does implicit voting matter? Coalitional bargaining in the EU legislative process}

Cesar Garcia Perez de Leon

European Union Politics 2012 13: 513 originally published online 3 October 2012 DOI: $10.1177 / 1465116512453883$

The online version of this article can be found at:

http://eup.sagepub.com/content/13/4/513

Published by:

@SAGE

http://www.sagepublications.com

Additional services and information for European Union Politics can be found at:

Email Alerts: http://eup.sagepub.com/cgi/alerts

Subscriptions: http://eup.sagepub.com/subscriptions

Reprints: http://www.sagepub.com/journalsReprints.nav

Permissions: http://www.sagepub.com/journalsPermissions.nav

>> Version of Record - Nov 18, 2012

OnlineFirst Version of Record - Oct 3, 2012

What is This? 
Does implicit voting matter? Coalitional bargaining in the EU legislative process
(C) The Author(s) 2012

Reprints and permissions: sagepub.co.uk/journalsPermissions.nav DOI: I0.I I77/I465II65I2453883 eup.sagepub.com

(SAGE

\title{
Cesar Garcia Perez de Leon
}

Sciences Po Paris, France

\begin{abstract}
This article examines how decision makers in the EU legislative process reach consensual decisions through the mechanism of 'implicit voting'. I introduce a spatial model of coalitional bargaining using a utility function incorporating decision makers' considerations of the policy gains they expect to obtain from the outcome and the policy concessions they need to give other decision makers so as to have the outcome accepted. The model predicts the formation of a compact coalition, which will be able to implement the final policy. As a compact coalition typically integrates a majority of like-minded legislators, consensual outcomes reached through coalition formations are likely to occur under conditions of preference polarization and reflect ideological choices towards one side of the political spectrum. The empirical evaluation of the model for 44 proposals and III issues of the EU legislative process requiring qualified majority voting confirms the expectations of the model and suggests that implicit voting is specifically relevant to explaining decisions leading to high or low levels of policy change.
\end{abstract}

\section{Keywords}

Coalition formation, cooperative game theory, decision-making, EU legislative process

\section{Introduction}

In the legislative process of the European Union (EU), member governments and supranational institutions regularly negotiate the passage of new legislation involving policy change. Inductive accounts of the legislative process show that decision

\section{Corresponding author:}

Cesar Garcia Perez de Leon, Centre d’Etudes Européennes - Sciences Po, 27 rue St. Guillaume, 75337 Paris Cedex 07, France.

Email: cesar.garciaperezdeleon@sciences-po.org 
makers of the EU commonly take decisions through 'implicit voting' (Golub, 1999, 2007; Hayes-Renshaw et al., 2006; Naurin and Wallace, 2008; Novak, 2010). Implicit voting refers to the mechanism by which decision makers participating in the process estimate the existence of an effective qualified majority coalition in negotiations preceding the final agreement, so that an actual vote may not take place and decisions are officially adopted 'by consensus'. The testimony of Dutch national representative Leendert Bal is illustrative in this regard:

If an observer were to attend Council meetings he or she would notice next to no evidence of a qualified-majority voting. It is unusual for presidencies to ask delegations to vote. The official explanation is that presidencies will seek consensus around the table and will thus avoid isolating colleagues. The expression of noblesse oblige is of course very welcome but it is only part of the explanation. Qualified-majority voting is like the sword of Damocles hanging above the negotiation table. It is in the mind of everyone. The Presidency, the Commission and delegations assess the state of the negotiation - almost permanently and automatically - in terms of whether there is a qualified majority or a blocking minority. (Bal, 2004: 129)

In spite of the attested occurrence of implicit voting in the EU, theoretical models dealing with negotiations in the EU have commonly focused on unanimous consent (Schneider et al., 2010; Thomson et al., 2006), leaving open the question of whether the 'shadow of the vote' has any influence on consensus-building. This article delineates a new model of coalition formation, explaining how and under what analytical conditions decision makers reach legislative decisions under the implicit application of a qualified majority rule. The implications of the model are evaluated across a large number of negotiations in the EU legislative process.

The model is a spatial voting game in which coalitions of decision makers with spatial policy preferences simultaneously offer proposals for a policy compromise to a sufficient number of voters who will implicitly be necessary to complete the qualified majority that constitutes a winning coalition. The model crucially assumes that the decision makers' incentives to choose a policy compromise strictly depend on the balance between the policy gains they obtain from the coalitional compromise and the policy concessions they need to give to other members of the coalition in order to see this compromise being accepted. If a qualified majority coalition offers a compromise for which no decision maker inside the coalition has incentives to renege on in favor of another alternative, such a compromise will be selected as the final policy to be implemented as common legislation.

The composition of a winning coalition and the content of its compromise proposal are the outcome of bargaining reflecting on the relative positions, power and salience of decision makers. According to the behavioural rationale posited by the model, each decision maker's payoff for accepting a coalitional compromise depends on a combination of policy gains and policy concessions. A decision maker who is to make a compromise with other actors in a given coalition may consider the opportunity to switch to an alternative coalition offering a 
compromise closer to her ideal preference. If, however, in comparison to the previous coalition the concessions she has to make to the members of this second coalition outweigh the policy gains she obtains, the decision maker will not have incentives to switch and thus will accept the original compromise. The model predicts that decision makers will select the policy compromise offered by the more compact coalition: the winning coalition in which the differences among each of the decision makers' policy position and the coalitional compromise are less pronounced.

Analytically, the formation of compact coalitions implies that legislative outcomes will have the imprint of the ideological choice preferred by a majority of decision makers. Accordingly, the basic implication of the proposed model is that implicit voting should be influential under conditions of ideological divergence in the EU legislative scene. The empirical estimation of this implication relies on a comparison between the compact coalition model and a model of unanimous bargaining for 44 proposals and 111 issues requiring qualified majority voting (QMV), obtained from the Decision Making in the European Union dataset (Thomson et al., 2006).

The article is organized as follows. In the first part, I discuss the literature on modelling EU decision-making and the implications of implicit voting. Subsequently, the model is presented and a case of an EU legislative negotiation under co-decision is introduced to illustrate the reasoning of the model. Finally, I address the quantitative evaluation of the model.

\section{Modelling decision-making in the cooperative environment of the EU}

Efforts to model how decisions in the EU are reached play a predominant role within the existing literature. The pioneering contributions on the subject conceived the decisional process as binary agenda non-cooperative games and focused on the effect that formal procedures have on decision-making outcomes (Crombez, 2000; Perez de Leon, 2011; Steunenberg and Selck, 2006; Tsebelis, 1994; Tsebelis and Garrett, 2001). Procedural models introduce important insights regarding inter-institutional dynamics and the general reform capacity of the EU. However, their non-cooperative assumptions, positing a strategic advantage for legislators preferring the status quo, have proved ill equipped to explain the tendency of EU decision makers to frequently reach consensual compromises (Achen, 2006b; König and Junge, 2009; Mattila and Lane, 2001; Selck, 2005). In this respect, cooperative models, allowing informal interactions among decision makers, offer a more plausible explanation of decision-making outcomes in the cooperative environment of the EU and have provided more accurate forecasts (Thomson et al., 2006; see, for discussion, Schneider, 2008). The vast majority of cooperative models applied to the EU are bargaining models where the formal decision rule does not condition the behaviour of decision makers because decisions are taken by unanimity (Achen, 2006a; Arregui et al., 2006; Bailer and 
Schneider, 2006; Bueno de Mesquita, 1994; Schneider et al., 2010; Van den Bos, 1991). Thus, the decision-making process appears universally inclusive, representing the interests of all decision makers.

Such a perspective crucially changes if the effect of the decision rule is integrated into informal negotiations. Implicit voting restricts the opportunities decision makers have under unanimity principles to stubbornly claim a major representation of their particular interests. Instead, decision makers have incentives to form a majority coalition with like-minded policy legislators. As a consequence, unlike under unanimous voting, implicit voting is likely to generate compromises that reflect a clearer ideological direction towards one side of the political spectrum.

The informal process by which decision makers take a decision by majority voting has been extensively studied by spatial models of coalition formation in the tradition of cooperative game theory (Bräuninger, 2007; Grofman, 1982; McKelvey et al., 1978; Owen, 1995; Schofield, 1995, 2008; Sened, 1996). In the context of the EU legislative process, however, there is little theoretical research on how the mechanism operates. To date, the coalition formation perspective has been represented only in the cooperative approach of Boekhoorn et al. (2006). Building on Axelrod's conflict of interest theory (Axelrod, 1970), this work posits a 'collective good' assumption by which players have incentives to form a winning coalition with minimal conflict. In contrast, the coalitional model presented here directly introduces a behavioural assumption to the individual utility of players, stating that no player will join a winning coalition if there is another winning coalition providing higher individual policy rewards. The focus on individual rationality provides solid micro-foundations explaining incentives for why decision makers cooperate, and posits a coalitional rationale distinct from the tendency to seek 'equitable' centripetal focal points (see Fiorina and Plott, 1978; McKelvey and Ordeshook, 1990) or the willingness to avoid internal conflict within a coalition (Boekhoorn et al., 2006). This perspective on the individual rationality of decision makers allows us to directly compare the operation of the coalitional mechanism against the unanimity mechanism posited by bargaining models, thus providing a straightforward way to evaluate the incidence of implicit voting.

\section{The model}

\section{Structure of the decision-making game}

A committee of a simple decision-making voting game (see Felsenthal and Machover, 1998; McKelvey et al., 1978; Owen, 1995) shall be set up in order to characterize how decision makers take decisions under the implicit application of a majority rule. Let $N$ be the set of players who are decision makers attempting to influence the outcome of legislative negotiations. Let $C \subseteq N$ be the coalitions that players can form, and $v$ a mapping that assigns payoffs to each coalition. In the simple game, only the winning coalition, $W$, gathering at least a qualified majority 
of the weighted votes of the committee can ensure the acceptance of a final policy proposal and impose it on the whole assembly of the players, so that

$$
W=\left\{C \subseteq N|| C \mid>\frac{3}{4}\right\}
$$

where $|C|$ denotes the number of weighted votes in a coalition $C$. The final outcome takes the form in which the winning coalition is assigned the total value of the game (that is, the total payoffs of the game, which its members are to divide among themselves), while losing coalitions get nothing, so that the solution of the game is defined by the characteristic function that specifies that $W=\{C \mid v(C)=1\}$. The characteristic function thus states that any player can secure a payoff from the game only by being member of the winning coalition. Even if a player considers the status quo to be a valuable outcome, the characteristic function tells us that the player can secure this outcome only if she obtains it through the formation of a winning coalition. Otherwise she will end up with no payoff or, equivalently, with a utility loss worse than the status quo, such as the damaging of institutional relationships. ${ }^{1}$ Finally, we need to spell out that a simple game is proper if, for every coalition $C \subseteq N$, exactly one $C, N-C$, is winning. That is, only one contemporary subset of players may form a winning coalition, so that there can be no ties.

We develop this scheme further by integrating empirically oriented features of a legislative process. Suppose that conflict among decision makers occurs over issue alternatives concerning how a policy is to be defined, as when they have to choose between adopting more or less stringent regulatory measures for environmental policy or higher or lower harmonization standards of safety in transport policy. We further note that most proposals submitted for legislation are multidimensional, so that decision makers are to decide simultaneously on two or more issues to adopt the final policy. In particular, let us adopt a spatial representation. Let $M=\{1,2,3, \ldots m\}$ be the set of all issues represented in an m-dimensional Euclidian metric space $R^{m}$. Let $A$ be the real number segment describing the set of alternative outcomes the players confront among the larger set $M$, so that $A \in R^{m}$ is the convex hull representing the Pareto set of the game. Let any player have an ideal position in the space, denoted as $x_{i}$.

I define the utility function of a player as incorporating the policy gains the player is to obtain from an outcome and the policy concessions the player needs to give other players in order to get this outcome accepted. In evaluating alternative outcomes, any player chooses the outcome for which the combination of policy gains and policy concessions offers her a greater utility. To capture this behavioral rationale, I thus define the preference of a player for an outcome as the sum of the player's Euclidean metric distance between the ideal position of the player and the policy outcome and the distance between each of the other players' position and the outcome, divided by the number of partners integrating the assembly or group in which the player participates. Formally, let $U$ be a utility function representing the 
preference profile of all players on $A$. Then, for any actor $i \in N$ and any outcome $\theta \in A$, there is a point $x_{i} \in R^{m}$ such that

$$
U_{i}(\theta)=h\left(\frac{\sum_{j \in N}\left(\left\|\theta-x_{i}\right\|+\left\|\theta-x_{j}\right\|\right)}{\sum_{j \in N}}\right)
$$

where $h$ is a decreasing function on the outcome and $i \neq j$. The first term in the numerator of the main expression equals the policy gains that player $i$ estimates from the policy outcome, these gains being larger the less the Euclidian distance from the ideal position of the player to the outcome. The second term in the numerator equals the policy concessions that each of the other players, $j$, claim in exchange for implementing this outcome. The assumption that a player will be willing to give policy concessions follows naturally from the fact that only players who are represented in the winning coalition obtain a payoff from the game. If a player does not give other players sufficient concessions, the derived increase in disutility for these other players will make them choose a different partner and, a fortiori, a different outcome. Players who are distant from the policy outcome are more 'expensive' to the rest of the players and need to give more concessions. It is important to note that, owing to the different policy positions of each player, the policy concessions they claim will differ accordingly. A player thus considers the gains and costs for every other player separately and then aggregates these quantities to define her total utility from the coalition. In addition, when two players have the same position, this will also be reflected in the outcome. As a consequence, and since no concessions are required, players with the same position are treated here as a single player.

Finally, the division by the total number of partners in the group corrects for the effect that groups of more players will automatically give less utility to the player, because she will need to give more concessions even if other players are close in the policy space.

\section{Coalitional bargaining: The compact coalition solution}

In the voting spatial game just defined, players have to select a policy outcome $\theta$ over all possible alternatives that will be supported by a winning coalition. How is this policy outcome to be found? Following McKelvey et al.'s (1978) conception of competition among coalitions, I represent the selection of an outcome as a process in which potential coalitions compete in offering proposals for a policy compromise to individual players in order to gain sufficient support to form a winning coalition that will enforce the policy.

In order to define these compromise proposals, we first need to know more about the players. Following standard assumptions of cooperative bargaining 
models (Achen, 2006a; Arregui et al., 2006; Bueno de Mesquita and Stokman, 1994; Van den Bos, 1991), I define a player $i$ as holding three characteristics by which the player can exert influence over the content of a policy. These characteristics are common knowledge, so that decision-making occurs under complete information. First, as already noted, a player has a policy position, $x_{i}$, in an m-dimensional policy space. Other things being equal, players can exert more influence in negotiations when their position is proximate to that of other players. Conversely, players holding extreme preferences will be less influential. Secondly, a player holds a certain amount of voting power or capabilities, $c$, which makes her more or less decisive in the adoption of a decision by the whole assembly. Finally, a player attaches a certain salience to issues. Salience captures how much the policy space means to the player, and hence determines how much effort the player is willing to spend on negotiations. Thus, a player can be described by a vector of three values, $\left(x_{i}, c_{i}, s_{i}\right)$, always in a Euclidian space with metric properties. ${ }^{2}$

When players form a coalition with other players, they will bargain over the composition of the policy position that the coalition is to adopt as a collective entity. Given the characteristics of the players, the bargaining process will derive a policy position of the coalition, which is defined as the vector consisting of the weighted average of the positions of all players, where the weights are their voting power and salience. The specific way in which the bargaining is conducted could, of course, be different. Any existing cooperative bargaining model could be used to obtain a policy position for the coalition without modifying the logical consistency of the model. The weighted average of positions or 'gravity centre' has, however, well-established support in the literature on coalition formation (see Boekhoorn et al., 2006; Grofman, 1982; Schofield, 1995, 2008). The specification of a bargaining process for defining coalition positions implies that any coalition position will be a feasible outcome, $\theta \in A$, and guarantees that the Pareto set $A$ will be finite.

We can now define a compromise proposal as a policy position of a coalition that can gather a sufficient number of votes to win. More precisely:

Definition $1 A$ compromise proposal of $C \subseteq N$ is an ordered pair $(\theta ; C)$, such that $\theta \in v(C)$ (McKelvey et al., 1978: 606)

The question that arises is whether there is a compromise proposal that satisfies these conditions, so that it can be selected as the final policy. In principle, any policy point from the set of alternatives $A$ that can be implemented by a winning coalition will be preferred by the players of this coalition and will constitute a viable compromise proposal. As long as two players who are pivotal in winning coalitions have diverging preferences for the proposals of these coalitions, no policy will dominate the others and the social choice will be cyclical. Given the application of a decision rule, it follows that a compromise proposal can be selected as a stable outcome only if it is undominated by any other policy. The set of undominated policies in set $A$ is known as the core. 
Traditional theories of coalition formation commonly face the prediction problem of an empty core with more than one policy dimension (McKelvey, 1976; Owen, 1995). Under a supermajority rule, the existence of the core can be guaranteed for two dimensions (Schofield et al., 1988). However, the size of the core may still be extremely large in these situations. I will show, however, that the behavioral assumption introducing motivations of policy gains and concessions into the preference profile of players induces a strict reduction of undominated points with any voting rule and, under conditions of asymmetry of player positions and weights, allows us to find a unique policy choice. I start presenting these results by first introducing a general definition derived from McKelvey et al. (1978: 606) stating that only the players who are at the intersection of coalitions, 'pivotal players', are relevant for the choice of a policy compromise:

Definition 2 For any two policy compromise proposals $(\theta ; C)$ and $\left(\theta^{\prime} ; C^{\prime}\right),(\theta ; C)$ is undominated by $\left(\theta^{\prime} ; C^{\prime}\right)$ if it is not the case that $u\left(\theta^{\prime}\right)>_{i} u(\theta)$ for all $i \in C \cap C^{\prime}$.

To see how this relation of dominance applies to the present model, we need only to compare the utility functions of players for the potential winning coalitions in a voting game. The player motivations for policy gains and policy concessions when joining a coalition reveal that undominated coalitions will be the coalitions in which the differences between each of the members' policy position and the coalitional compromise will be less pronounced than in any other coalition. I will refer to these coalitions as compact coalitions. ${ }^{3}$ The following result restates this finding, which, as for the following results, is formally proved in the Web Appendix.

Proposition 1 For any two proposals $(\theta ; C)$ and $\left(\theta^{\prime} ; C^{\prime}\right),(\theta ; C)$ is undominated by $\left(\theta^{\prime} ; C^{\prime}\right)$ if, given the preference profile $U$, it is not the case that $C^{\prime}$ is more compact than $C$, for all $i \in C \cap C^{\prime}$

From this proposition it follows that the existence of a set of compact coalitions in a simple game guarantees stable outcomes. We now demonstrate that such a set always exists if a game is proper and finite.

In a proper voting game, the odd number of votes allocated to players ensures that only a contemporary subset of winning coalitions will form. Moreover, when the number of players is finite and each coalition makes only one proposal, the set of feasible outcomes will be finite. Under these two conditions, the formation of a unique set of winning coalitions that are more compact than any other coalition outside this set is assured. It is also clear that there will always be an ordering of compact coalitions, so that it is impossible that compact coalitions 'mutually dominate' each other. Therefore, all points in the set will be undominated and the set will not be empty.

Proposition 2 In any finite and proper spatial voting game, there is always a set of compromise proposals offered by compact coalitions which dominate any other point 
outside the set, and which are undominated by any other point in the set. Let $k^{\text {com }} \subseteq A$ denote the set of compromise proposals offered by compact coalitions, then:

$\kappa^{\text {com }}=\left\{(\theta ; C) \in A \mid\right.$ for $\operatorname{no}\left(\theta^{\prime} ; C^{\prime}\right) \in A$ it is the case that $u\left(\theta^{\prime}\right)>{ }_{i} u(\theta)$ for all $\left.i \in v(C)\right\}$

$$
\kappa^{c o m} \neq \emptyset
$$

Expression (2) is a standard definition of the core. It differs only in the nonstandard definition of compromise proposals, as induced by the utility functions of players based on combined policy gains and concessions. Expression (3) simply restates that the compact coalition core is not empty.

The existence of a non-empty compact coalition set constitutes the general solution of the game. As in other core-related solutions, there is no insistence that the set $k^{\text {com }}$ contains only one element (see Owen, 1995). Alternatives in the set may be only weakly preferred to other alternatives in the set by all pivotal actors. Yet the cases where we find several stable outcomes are special cases in which there is perfect symmetry in the distribution of player positions and player weights in the policy space. Such conditions of symmetry are rare. In most cases we will have only one element in the set.

Proposition 3 In any finite and proper spatial voting game, under conditions of asymmetry in the distribution of player positions and player weights, the set of compromise proposals offered by compact coalitions contains a unique point that strictly dominates any other point outside the set.

The results just presented allow us to predict a set of stable policy outcomes that will be supported by a qualified majority of decision makers in committees such as the EU legislature. Based on the behavioral rationale that decision makers consider both policy gains and concessions in their choice of a common policy, they will select a policy implemented by a coalition that is more compact than the rest. The compact coalition constitutes a stable outcome because the combination of gains and concessions in this coalition turns out to be more rewarding for any pivotal member in the coalition when compared with other alternatives. Whereas symmetric conditions produce several compact coalitions of indifferent players, asymmetric conditions bring together like-minded legislators in a unique compact coalition. A single compact coalition is thus expected to form in policy-making situations where decision makers compete to bring about a policy change towards a determined ideological direction.

\section{Coalition formation in the EU legislative process}

The model is illustrated for the case concerning the negotiation for the adoption of EU Directive 2002/7/EC by co-decision, relating to the maximum authorized 
dimensions and weights for road vehicles circulating within the Community. The data for this case are part of a larger dataset of the Decision Making in the European Union (DEU) project, which collects information about legislative proposals for the EU15. Dedicated to the quantitative evaluation of the model, more details about the structure of the data are explained in the next section. The interest now is to show the reasoning of the coalitional model.

The first information we need to apply to the model refers to the institutional structure of the voting game, that is, the quota of votes needed to form a winning coalition that can implement the decision. In order to represent the EU voting game under co-decision (Art. 169 TEU, amended by Art. 294 of the Treaty of Lisbon as 'ordinary legislative procedure'), I adopt the DEU modelling strategy for cooperative games. This strategy 'endogenizes' the procedural power of EU institutions by always including them as members of the winning coalition (see Thomson and Stokman, 2006: 49-50). For the specific co-decision procedure, we consider only the members of the Council and the European Parliament (EP) as decisive players. Although the European Commission introduces the legislative proposal in the co-decision procedure, its exclusion as a decisive player is justified because its capacity to strategically vary its proposal is limited to the first stages of the procedure. ${ }^{4}$

These features are operationalized more precisely with the use of the Shapley Shubik Power Index, which measures the relative capacity of decision makers to turn a coalition from winning to losing (see Felsenthal and Machover, 1998). In the rule structure of the voting game for the EU15 regime, the governments in the Council need to gather 62 out of 87 votes to form a winning coalition, and under co-decision the EP is always required to complete the winning coalition. This is equivalent to saying that a winning coalition can form when the Council has gathered 0.69 of the total voting power and the EP 0.31. Translating the voting power scores into a voting rule or quota, the voting game for the EU co-decision procedure then takes the following form: ${ }^{5}$

$$
[62+25 ; 25,10,10,10,10,8,5,5,5,5,4,4,3,3,3,2]
$$

The data concerning the factors by which decision makers can influence the negotiation are their voting power, $c^{i}$, the initial declaration of preferences for the issues under discussion, $x_{i}$, and the importance they attach to the issues, $s_{i}$. Table 1 presents the information about these values for the proposal on Directive $2000 / 7 /$ EC. The voting power of each decision maker, $c_{i}$, is calculated with the Shapley Shubik Power Index. The voting power is proportional to the number of votes of each decision maker. Thus, big member states, with 10 votes, have voting power scores of 0.08 , whereas a small state such as Luxembourg has a score of 0.014. As noted, the EP always holds a voting power score of 0.31 . The two other values, $x_{i}$ and $s_{i}$, are derived from empirical information and are hence specific to the issues under negotiation. During the discussions of the proposal for Directive 2000/7/EC, decision makers declared discrepancies concerning two issues: the 
Table I. Positions, saliences and voting power in the proposal for Directive 2000/7/EC

\begin{tabular}{|c|c|c|c|c|c|}
\hline \multirow[b]{2}{*}{ Decision makers } & \multicolumn{2}{|l|}{$x_{i}$} & \multicolumn{2}{|l|}{$s_{i}$} & \multirow[b]{2}{*}{$c_{i}$} \\
\hline & Issue I & Issue 2 & Issue I & Issue 2 & \\
\hline Commission & 100 & 100 & 80 & 40 & 0 \\
\hline Belgium & 50 & 0 & 40 & 50 & 0.037 \\
\hline Denmark & 50 & 100 & 70 & 70 & 0.024 \\
\hline Germany & 100 & 0 & 90 & 90 & 0.080 \\
\hline Greece & 100 & 0 & 60 & 80 & 0.037 \\
\hline Spain & 50 & 0 & 90 & 90 & 0.066 \\
\hline France & 100 & 0 & 70 & 80 & 0.080 \\
\hline Ireland & & 0 & 50 & 50 & 0.024 \\
\hline Italy & 100 & 0 & 70 & 80 & 0.080 \\
\hline Luxembourg & 50 & 0 & 40 & 40 & 0.014 \\
\hline Netherlands & 0 & 0 & 90 & 80 & 0.037 \\
\hline Austria & 100 & 0 & 70 & 70 & 0.031 \\
\hline Portugal & 100 & 0 & 70 & 70 & 0.037 \\
\hline Finland & 50 & 0 & 90 & 80 & 0.024 \\
\hline Sweden & 50 & 0 & 90 & 80 & 0.031 \\
\hline UK & 50 & 70 & 50 & 70 & 0.080 \\
\hline EP & 50 & 100 & 80 & 40 & 0.310 \\
\hline
\end{tabular}

Notes: Issue I: Maximum length authorized to vehicles $=15 \mathrm{~m}$ ( 2 axles), $50=13.5 \mathrm{~m}$ ( 2 axles), $100=12 \mathrm{~m} \mathrm{(2}$ axles). Issue 2: Type of manoeuvrability of vehicles $=$ UNECE criteria of manoeuvrability, $70=$ no agreement with any proposed criteria, $100=$ Directive $97 / 27 / E C$ criteria of manoeuvrability.

accredited maximum length authorized for vehicles, and whether the type of manoeuvrability of vehicles should correspond to the criteria laid down by the United Nations Economic Commission for Europe (UNECE) or by EU Directive 97/27/ EC. The positions of decision makers and the importance they attach to these two issues are presented as a continuum for each issue of the proposal, representing the gradation between two extremes of a controversy, issue-by-issue. The status quo (SQ) is located at position 0 , and position 100 corresponds to the position of the decision maker favoring the most radical policy change in regard to the SQ.

It should be noted that the location of the status quo is not relevant for deducing which coalition will form in the cooperative voting game. Players will, no matter how close to or how far from the status quo this policy is, determinately prefer the policy that affords them more rewards in terms of gains and concessions. However, the reference to the SQ as point ' 0 ' in the policy space allows us to infer the degree of policy change generated by the legislative process (see Achen, 2006b; König and Junge, 2009) 


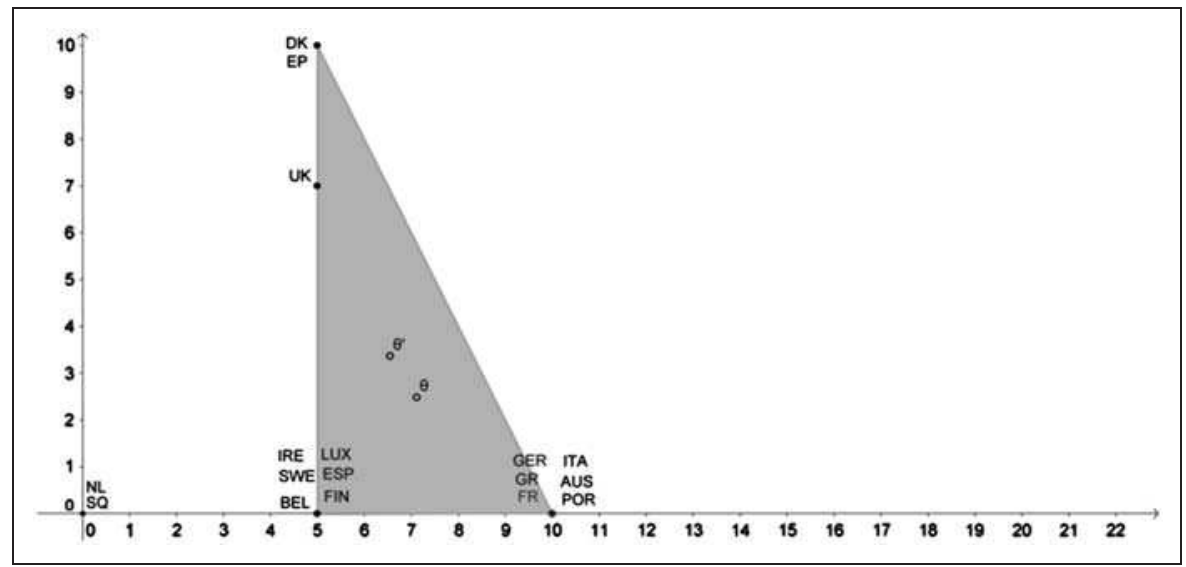

Figure I. Spatial model of coalitional bargaining in the negotiations of Directive 2000/7/EC. Notes: The horizontal dimension represents the first issue of the negotiations - dealing with the maximum length authorized to vehicles. The vertical dimension concerns the second issue - the criteria to determine the type of manoeuvrability of vehicles. AUS: Austria, BEL: Belgium, DK: Denmark, EP: European Parliament, ESP: Spain, FIN: Finland, FR: France, GER: Germany, GR: Greece, IRE: Ireland, ITA: Italy, LUX: Luxemburg, NL: Netherlands, POR: Portugal, SQ: status quo, SWE: Sweden, UK: United Kingdom.

With this information we can examine how the process of coalitional competition unfolds. The positions of the decision makers are represented in the twodimensional graph of Figure $1 .{ }^{6}$ Since the Netherlands appears isolated at position $(0,0)$, it is unlikely that this government lures other legislators to form a winning coalition. Instead, the coalitional bargaining is to be restricted to the triangleshaped area of the figure, where we find three distinctive groups of legislators around the positions $(100,0),(50,0)$ and $(50,100)$.

The model predicts the formation of a unique compact coalition offering the following compromise proposal: (71.03, 24.60: Germany, Greece, France, Italy, Austria, Portugal, Belgium, Spain, Luxembourg, Finland, EP). No pivotal decision maker in the coalition has incentives to renege on this compromise. As a consequence, the coalition is dominant.

Figure 1 represents the outcome of the compact coalition at point $\theta$. To see why this point is dominant, recall that, according to the preference function of decision makers, the combination of policy gains they obtain from a compromise and the policy concessions they would need to offer to the members of the coalition is to provide a better deal for themselves. In this instance, we may naively presume that the representatives of the EP would be tempted to look for another, more favorable deal. The EP, in reality, could offer a compromise proposal at $(65.43,33.66$ : EP, Denmark, UK, Germany, France, Italy, Belgium, Spain, Luxembourg, Sweden). This is point $\theta^{\prime}$ in the figure, which is closer to the position of the EP. However, the pivotal members who would be needed in both coalitions would 
endure heavier losses in this second coalition by integrating Denmark and the UK. Indeed, Denmark and the UK are more isolated than any other government in the legislative bargaining space, and they drive the outcome further away from the majority of governments. As a consequence, their inclusion in a coalition makes this coalition less compact when compared with the dominant (compact) coalition. For the EP this means that the majority of governments in the non-compact coalition will claim more policy concessions, and the EP will need to pay a substantial portion to them. In comparison with alternative proposals, the combination of total gains and concessions of the compact coalition offers a maximizing choice to the EP. The exact measures are shown in Table 2. The EP's utility from the compact coalition is 3.86 , while the alternative coalition gives a disutility of 5.57 units of combined distance of gains and concessions.

Leaving the compact coalition will entail a utility loss for the EP, because it would require more expensive adjustments between policy gains and concessions. Therefore, the supranational institution and all the pivotal member governments have no incentives to change their choice for the compact coalition, because this coalition will be dominant.

\section{Empirical accuracy of the compact coalition model: The relevance of implicit voting for EU policy change}

This section quantitatively evaluates the performance of the compact coalition model for 44 EU legislative proposals, containing 111 issues, which were decided under QMV. The objective of this evaluation is to assess whether implicit voting and its coalitional dynamics are relevant mechanisms by which decision makers reach consensual decisions in the EU.

The research design employed here consists of comparing the performance of the compact coalition model with that of the compromise bargaining model, which posits that the preferences of all decision makers are integrated into the decision, implying that consensus entails unanimous consent (Achen, 2006b; Thomson, 2011; Van den Bos, 1991). Attempts to falsify the impact of implicit voting from a simple comparison of the two models, however, involve certain difficulties. Part of the problem is that coalition formation and generalized bargaining may produce observational equivalence. It may be that the outcome selected by a qualified majority looks exactly the same as the outcome selected by the totality of actors in the whole assembly. To overcome this problem, I differentiate categories of outcomes that are expected to result from coalition formation. As conceived in the compact coalition model, coalition formation reflects a tendency of decision makers to seek reinforcement of like-minded partners in order to bring the outcome towards the ideological direction they prefer. In contrast, when decisions are taken by unanimous consent, we should expect that ideological factors play a minor role and that decision makers are willing to take the preferences of all legislators into account. In this view, I will tease out the influence of implicit voting on consensus-building by addressing the extent to which coalitional 
Table 2. Competing coalitions for the adoption of Directive 2000/7/EC

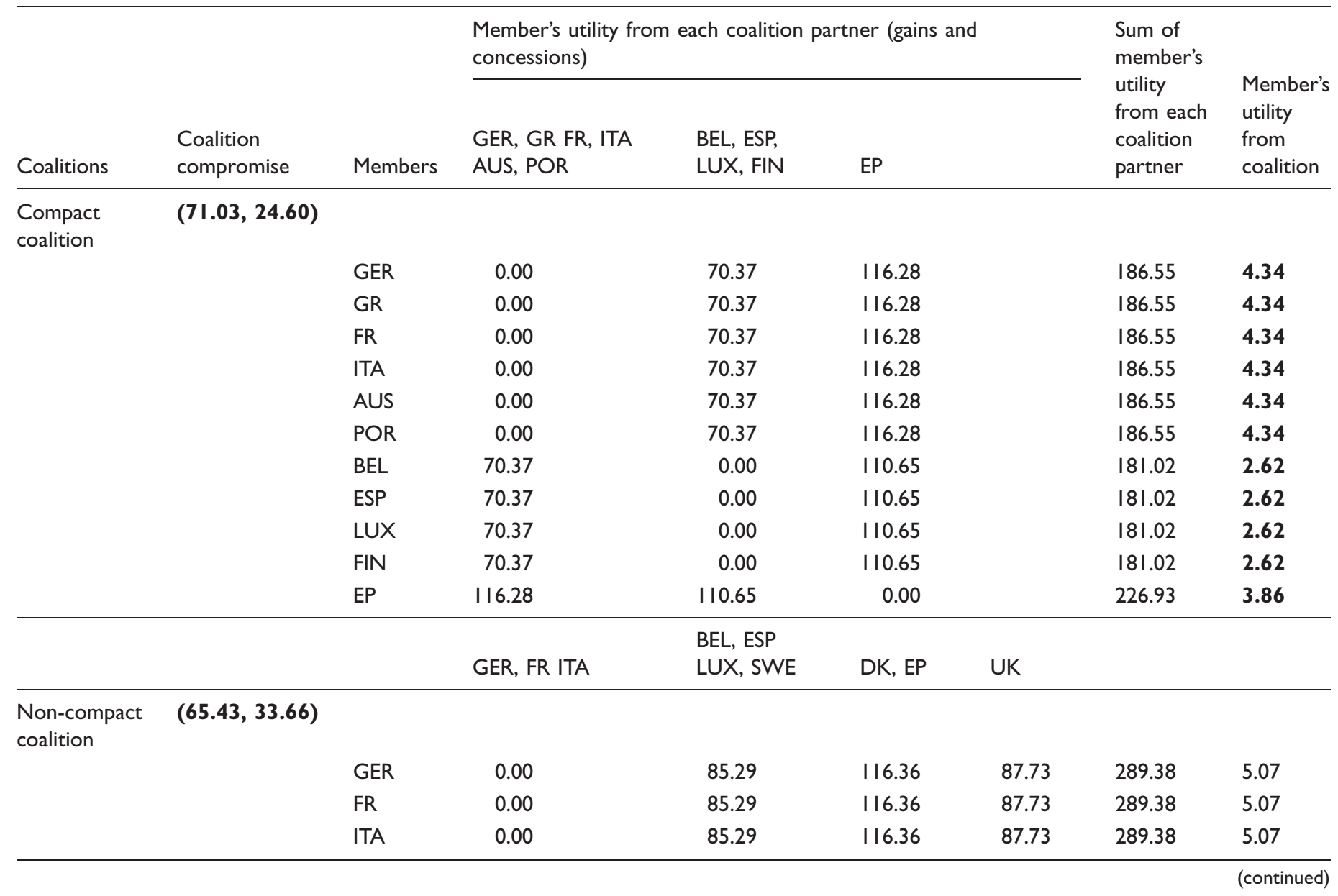




\begin{tabular}{|c|c|c|c|c|c|c|c|c|}
\hline \multirow[b]{2}{*}{ Coalitions } & \multirow[b]{2}{*}{$\begin{array}{l}\text { Coalition } \\
\text { compromise }\end{array}$} & \multirow[b]{2}{*}{ Members } & \multicolumn{4}{|c|}{$\begin{array}{l}\text { Member's utility from each coalition partner (gains and } \\
\text { concessions) }\end{array}$} & \multirow{2}{*}{$\begin{array}{l}\text { Sum of } \\
\text { member's } \\
\text { utility } \\
\text { from each } \\
\text { coalition } \\
\text { partner }\end{array}$} & \multirow{2}{*}{$\begin{array}{l}\text { Member's } \\
\text { utility } \\
\text { from } \\
\text { coalition }\end{array}$} \\
\hline & & & $\begin{array}{l}\text { GER, GR FR, ITA } \\
\text { AUS, POR }\end{array}$ & $\begin{array}{l}\text { BEL, ESP, } \\
\text { LUX, FIN }\end{array}$ & EP & & & \\
\hline & & BEL & 85.29 & 0.00 & 105.13 & 76.50 & 266.92 & 3.92 \\
\hline & & ESP & 85.29 & 0.00 & 105.13 & 76.50 & 266.92 & 3.92 \\
\hline & & LUX & 85.29 & 0.00 & 105.13 & 76.50 & 266.92 & 3.92 \\
\hline & & SWE & 85.29 & 0.00 & 105.13 & 76.50 & 266.92 & 3.92 \\
\hline & & DK & 116.36 & 105.13 & 0.00 & 107.58 & 329.08 & 5.57 \\
\hline & & EP & 116.36 & 105.13 & 0.00 & 107.58 & 329.08 & 5.57 \\
\hline & & UK & 87.73 & 76.50 & 107.58 & 0.00 & 271.81 & 3.53 \\
\hline
\end{tabular}

Notes: The member's utility from the coalition is the sum of utilities from joining each of the coalition partners divided by the total votes of the partners in the coalition. See Figure I for abbreviations. 
predictions tend to correspond to observed outcomes reflecting a choice from one side of the ideological spectrum.

In the operationalization of the comparison between coalitional and unanimous mechanisms of consensus, the compromise model has been chosen because it uses the same 'parameters' as the compact coalition model. It also weights the positions of the players, where the weights are their voting power and salience, but it does so for all the players of the committee. Since the compromise model appeals to the same inputs as the compact coalition model, it allows us to obtain a direct comparison between implicit voting and unanimous consent. ${ }^{7}$

Information on the legislative decisions has been obtained from the dataset of the DEU research project (Thomson et al., 2006). Through expert interviews, the DEU programme collects data on positions, salience and outcomes for 66 legislative proposals and 162 issues, decided by the co-decision and consultation procedures and introduced by the Commission between 1999 and 2000. Here only 44 proposals decided under QMV are examined, because these are the only proposals where implicit voting is relevant. All selected proposals dealt with issues that raised controversy among the decision makers and aroused public attention. Therefore, seemingly technical and routine proposals were excluded from the sample. Information about the actors' positions and saliences was collected after the Commission had issued the proposals and before the legislative act was adopted. Yet the actual outcomes are also included in the dataset. As we saw in the case illustrating the model, this information is presented in an issue continuum where the SQ is located at position 0 and position 100 corresponds to the most distant position from the SQ. In this manner, estimation about the degree of policy change is possible. The more distant outcomes are from the SQ, the more policy change the legislative process generates.

The evaluation of the models uses the standard testing procedure for deterministic models consisting of comparing the distance between predicted outcomes and observed outcomes (see Bueno de Mesquita and Stokman, 1994; Schneider et al., 2010; Thomson, 2011; Thomson et al., 2006). More precisely, the testing measure employed is the Mean Absolute Error (MAE), that is, the average size of the forecasting error. The accuracy of predictions is then estimated by the degree of the forecasting error they produce. As is well known, since deterministic models predict equilibrium points that are assumed to occur with certainty (see Achen, 2006b; Junge, 2010; Morton, 1999; Signorino, 1999), they are not amenable to probabilistic statistical evaluation. Alternative tests to estimate the quality of the model, such as normalized predictions (Bueno de Mesquita and Stokman, 1994) or hit rates (Achen, 2006b; Schneider et al., 2010), could have been used. However, given the structure of the data-generation process of deterministic models, the discrepancies between observed and predicted outcomes provide a sensible measure of forecasting accuracy (Achen, 2006b; Morton, 1999) and serve well the purpose of comparing implicit voting and unanimous consent.

The first test I conduct evaluates the performance of the compact coalition model and of the compromise model for all issues and by legislative procedure. 
Table 3. Mean Absolute Error of models for all decisions under co-decision (COD) and consultation (CNS) procedures of the EU legislative process

\begin{tabular}{llll}
\hline & \multicolumn{2}{l}{ QMV } & \\
\cline { 2 - 4 } Model & $\begin{array}{l}\text { COD } \\
(n=56)\end{array}$ & $\begin{array}{l}\text { CNS } \\
(n=55)\end{array}$ & $\begin{array}{l}\text { All issues } \\
(n=1 I I)\end{array}$ \\
\hline Median voter model & 30.64 & 30.62 & 30.63 \\
Compromise model & 27.28 & 23.84 & 25.56 \\
Compact coalition model & 26.84 & 25.54 & 26.19 \\
\hline
\end{tabular}

By doing so, we want to obtain a general assessment of the success of the models. For this purpose, the median voter has been used as a null model. The median provides atheoretical predictions, and therefore serves as a baseline to evaluate the quality of the two theoretical models. Table 3 reports the predictions of the models. Both models perform better than the median. The compromise model fares slightly better for all issues under QMV, with a MAE of 25.56 against the 26.19 of the compact coalition model. The differences, however, are not very big. For the codecision procedure, the most relevant EU procedure, the compact coalition model performs better, with a MAE of 26.84 against the 27.28 of the compromise model. Overall, coalition formation and generalized bargaining tend to offer very similar results in this comprehensive test. We can confirm that consensus is generally preferred by EU decision makers, yet we cannot confirm whether a majority of decision makers will be enough to make a consensual decision.

Despite the similarity of predictions, the association between the forecasts of the two models in a linear transformation, with a Pearson correlation of 0.58 , turns out to be lower than we had assumed. This indicates that the different causal mechanisms of the two models can also be witnessed in the data.

The second test performed seeks to evaluate more directly the impact of implicit voting by focusing on its causal mechanism. For this purpose, I differentiate outcomes reflecting ideological choices that are expected to result from coalition formation. Given the structure of our data, ideological choices are represented as outcomes pointing to more or less pronounced policy change. ${ }^{8}$ I thus perform the MAE test for different levels of policy change, ranging from minimum to pronounced policy change. I expect that, if ideological factors are influential, decision makers will tend to build majoritarian coalitions, which in turn will cause outcomes to be at a determined level of policy change. By contrast, I expect that if ideological factors have a minor effect, decision makers will prefer to form a 'grand coalition' of all the actors, implying a lesser impact of coalition formation on the level of policy change. Naturally, our evaluation of implicit voting in this design needs to be posited in relative terms. If, relative to the compromise bargaining model, the compact coalition model performs better for a determined level of 
Table 4. Mean Absolute Error of compromise model and compact coalition model for different levels of policy change in EU legislative output

\begin{tabular}{|c|c|c|c|}
\hline & $\begin{array}{l}\text { Minimal policy } \\
\text { change }\end{array}$ & $\begin{array}{l}\text { Moderate policy } \\
\text { change }\end{array}$ & $\begin{array}{l}\text { Pronounced policy } \\
\text { change }\end{array}$ \\
\hline Model & $\begin{array}{l}\text { Outcome range: } \\
0-30(n=27)\end{array}$ & $\begin{array}{l}\text { Outcome range: } \\
30-60(n=36)\end{array}$ & $\begin{array}{l}\text { Outcome range: } \\
60-100(n=48)\end{array}$ \\
\hline Compromise model & 42.92 & 13.84 & 25.10 \\
\hline Compact coalition model & 36.30 & 23.73 & 22.30 \\
\hline
\end{tabular}

policy change, then policy change will be driven more by implicit voting and less by unanimous consent. If, on the contrary, this is not the case, we should conclude that implicit voting has no influence on consensus-building and that decision makers are inclined to adopt all-inclusive compromises by unanimity.

Table 4 shows the MAE for three levels of policy change. According to their location on an issue continuum bounded between 0 and 100, observed outcomes are coded as promoting low, moderate or pronounced policy change. We can see that the prediction of the compact coalition model is more uniformly distributed than the prediction of the compromise model, as estimated by the error the models yield for the three levels of policy change.

This result suggests that implicit voting does have an influence on the way consensus is taken, and, ultimately, on the ideological direction of this consensus. The fact that both minimal policy change and pronounced policy change are better predicted by the compact coalition model informs us that decision makers attempt to align themselves with other like-minded partners in order to influence the policy outcome they prefer. In addition, they are willing to make policy concessions to those partners in order to increase the chances that a majority will select a policy close to this outcome.

Yet the compromise model fares remarkably better when decisions are moderate. Given our testing measure, the fact that the mean-oriented compromise model is favored in situations of medium levels of policy change is not surprising (see Bueno de Mesquita, 2004). However, the differences in prediction are wide enough to prompt some informed conclusions. The 'grand coalition' thus appears to be a superior mechanism when conditions for consensus reflect the existence of a centric voter. In this case, excluding any decision maker from the compromise seems to be either unsuitable or unnecessary. Decision makers prefer to disregard minor ideological divergences and take everyone on board in the final decision. The compact coalition model also predicts well in moderate decisions, but not as well as the compromise model. In this view, the final interpretation derived from the evidence is that, when controversy is less acute, decision makers have a tendency to act unanimously. However, when issues are more ideologically polarized, implicit 
voting appears to be a more determinant mechanism in the configuration of consensual decisions.

\section{Conclusion}

Theoretical explanations and empirical assessments of how consensual agreements in the EU are reached have commonly focused on unanimous consent. However, the question of whether consensus may be reached under the 'Damocles sword' of a qualified majority has received little rigorous theoretical treatment. The article addresses this shortcoming with a model of coalition formation positing that decision makers select a majoritarian compromise by pondering the policy gains they are to obtain from a compromise and the policy concessions they need to give in order to see this outcome supported by a qualified majority. The result of the legislative bargaining in which decision makers evaluate different choice alternatives is the formation of a compact coalition to implement the final policy.

At the theoretical level, the compact coalition model yields the finding of a stable solution for finite and proper spatial voting games, which usually have an empty core. The proposed solution thus relates to other classic core solutions of well-established cooperative theories, and suggests a refinement to these solutions. This article does not intend to suggest that decision makers' motivations to exchange policy gains and concessions in order to reach an agreement with a like-minded majority exist in every political situation. Nonetheless, it is natural to assume that they do exist in cooperative decision-making environments where the penalization for not reaching an agreement is high. The EU legislative process is commonly perceived as such a cooperative environment. At the empirical level, the quantitative evaluation of the model yields mixed results. The evidence suggests that, in the EU legislative process, ideological majorities vote implicitly in order to drive consensus towards minimum or pronounced levels of policy change. However, when majorities have moderate policy choices, they are inclined to take everybody on board and unanimous consent remains a powerful mechanism.

\section{Acknowledgements}

I am grateful to Gerald Schneider and several anonymous referees for their comments, to the EU 7th Framework Programme for financial support (Grant 238438), and to Robert Thomson and Bernard Steunenberg for letting me access replication material.

\section{Notes}

1. Specifically, let $u_{i}$ be the utility that any player can secure by acting alone, then $u_{i} \leq w_{i}$ for all $i \in C$ and $w \in v(C)$.

2. In the set of issues $M=\{1,2,3 \ldots m\}$, where $m \geq 1$, a player's position on an issue, and the influence she can exert on the issue, may differ from that taken on another issue. Such variations will be reflected in the overall influence the player exerts on a given policy vector $\theta \in A$.

3. The word 'compact' is unrelated to and should not be confused with the notion of 'compactness' and 'compact set', which is used to refer to closed and bounded sets, which contain an infinite number of choices. 
4. The modelling strategy of the co-decision procedure thus corresponds to the Shapley Shubik Index Second Variant of EU inter-institutional interaction specified in the DEU research design. In the larger dataset, I also consider proposals under the consultation procedure, where the Commission has the possibility to change its proposal at any stage, while the EP has only a consultative function. The form of the voting game remains as indicated. However, I reverse the roles of the Commission and the EP, so that, in the consultation procedure, it is the Commission that is a decisive player and has a voting power score of 0.31 , whereas the EP is a dummy player. This corresponds to the Shapley Shubik Index First Variant of the DEU research design.

5. When some member states are indifferent to issues under discussion and do not participate in the process of its resolution, the quota will be readjusted. The proposal illustrated here offers an example: Ireland, holding 3 votes, is indifferent regarding the first issue, so that the Council has 84 active votes. Then a winning coalition will need 60 votes of the Council and 24 of the supranational institution.

6. For simplicity of exposition I have not represented the power and salience of decision makers in the graph. Note, however, that these weights are reflected in the two alternative outcomes.

7. One difference between the two models, however, is the coding of indifferent actors. Proponents of the compromise model give indifferent actors a position halfway between the proposal of the Commission and the reference point. I have maintained their original coding in running their model here.

8. For a related test on the ability of models to predict change from the status quo, see Achen (2006b).

\section{References}

Achen C (2006a) Institutional realism and bargaining models. In: Thomson R, Stokman F, Achen $\mathrm{C}$ and König $\mathrm{T}$ (eds) The European Union Decides. New York: Cambridge University Press, 86-123.

Achen C (2006b) Evaluating political decision-making models. In: Thomson R, Stokman F, Achen C and König T (eds) The European Union Decides. New York: Cambridge University Press, 264-298.

Arregui J, Stokman F and Thomson R (2006) Compromise, exchange and challenge in the European Union. In: Thomson R, Stokman F, Achen C and König T (eds) The European Union Decides. New York: Cambridge University Press, 153-177.

Axelrod R (1970) Conflict of Interest: A Theory of Divergent Goals with Application to Politics. Chicago: Markham.

Bailer S and Schneider G (2006) Nash versus Schelling? The importance of constraints in legislative bargaining. In: Thomson R, Stokman F, Achen $\mathrm{C}$ and König T (eds) The European Union Decides. New York: Cambridge University Press, 153-177.

Bal LJ (2004) Member states operating in the EU Council of Ministers: Inside impressions. In: Meerts $\mathrm{P}$ and Cede F (eds) Negotiating European Union. New York: Palgrave Macmillan, 127-142.

Boekhoorn V, Van Deemen A and Hosli M (2006) A cooperative approach to decisionmaking in the European Union. In: Thomson R, Stokman F, Achen C and König T (eds) The European Union Decides. New York: Cambridge University Press, 178-210.

Bräuninger T (2007) Stability in spatial voting games with restricted maximizing. Journal of Theoretical Politics 19(2): 173-191. 
Bueno de Mesquita B (1994) Political forecasting: An expected utility method. In: Bueno de Mesquita B and Stokman F (eds) European Community Decision Making. New Haven, CT: Yale University Press, 71-104.

Bueno de Mesquita B (2004) Decision making models, rigor and new puzzles. European Union Politics 5(1): 125-138.

Bueno de Mesquita Bruce and Frans Stokman (1994) European Community Decision Making. New Haven, CT: Yale University Press.

Crombez C (2000) Institutional reform and co-decision in the European Union. Constitutional Political Economy 2: 41-57.

Felsenthal D and Machover M (1998) The Measurement of Voting Power: Theory and Practice. Cheltenham: Edward Elgar.

Fiorina M and Plott C (1978) Committee decisions under majority rule: An experimental study. American Political Science Review 72: 575-598.

Hayes-Renshaw F, Van Aken W and Wallace H (2006) When and why the EU Council of Ministers votes explicitly. Journal of Common Market Studies 44(1): 161-194.

Garcia Perez de Leon C (2011) Coalition formation and agenda setting in EU environmental policy after the enlargement. Les Cahiers européens de Sciences Po, 05. Paris: Centre d'études européennes at Sciences Po.

Golub J (1999) In the shadow of the vote? Decision making in the European Community. International Organization 53(4): 733-764.

Golub J (2007) Survival analysis and European Union decision-making. European Union Politics 8(2): 155-179.

Grofman B (1982) A dynamic model of protocoalition formation in ideological 'N' space. Behavioral Science 27(1): 77-90.

Junge D (2010) Game theoretic models and the empirical analysis of the EU. In: König T, Tsebelis G and Debus M (eds) Reform Processes and Policy Change: Veto Players and Decision-Making in Modern Democracies. New York: Springer Verlag, 247-268.

König T and Junge D (2009) Why don't veto players use their power? European Union Politics 10(4): 507-534.

McKelvey R (1976) Intransitivities in multidimensional voting models and some implications for agenda control. Journal of Economic Theory 12: 472-482.

McKelvey R and Ordeshook P (1990) A decade of experimental research on spatial models of elections and committees. In: Enelow J and Hinich M (eds) Advances in the Spatial Theory of Voting. Cambridge: Cambridge University Press, 99-144.

McKelvey R, Odeshook P and Winer M (1978) The competitive solution for N-person games without transferable utility. With an application to committee games. American Political Science Review 72(2): 599-615.

Mattila M and Lane J-E (2001) Why unanimity in the Council? A roll-call analysis of Council voting. European Union Politics 2(1): 31-52.

Morton R (1999) Methods and Models. Cambridge: Cambridge University Press.

Naurin D and Wallace H (2008) Unveiling the Council of the European Union. Games Governments Play in Brussels. New York: Palgrave Macmillan.

Novak S (2010) Decision rules, social norms and the expression of disagreement: The case of qualified majority voting in the Council of the European Union. Social Science Information 49(1): 49-83.

Owen G (1995) Game Theory, 3rd edn. San Diego: Academic Press.

Schneider G (2008) Neither Goethe, nor Bismarck: On the link between theory and empirics in Council decision-making studies. In: Naurin D and Wallace H Unveiling the Council of 
the European Union. Games Governments Play in Brussels. New York: Palgrave Macmillan, 277-289.

Schneider G, Finke D and Bailer S (2010) Bargaining power in the European Union: An evaluation of competing game-theoretic models. Political Studies 8(1): 85-103.

Schofield N (1995) Coalition politics: A formal model and empirical analysis. Journal of Theoretical Politics 7(3): 245-281.

Schofield N (2008) The Spatial Model of Politics. Abingdon: Routledge.

Schofield N, Grofman B and Feld S (1988) The core and the stability of group choice in spatial voting games. American Political Science Review 82(1): 195-211.

Selck T (2005) Explaining the absence of inertia in European Union legislative decisionmaking. Journal of Common Market Studies 43(5): 1055-1070.

Sened I (1996) Coalition formation: Theory and evidence. Journal of Politics 58(2): 350-375.

Signorino C (1999) Strategic interaction and statistical analysis of international conflict. American Political Science Review 93(2): 279-297.

Steunenberg B and Selck T (2006) Testing procedural models of EU legislative decisionmaking. In: Thomson R, Stokman F, Achen C and König T (eds) The European Union Decides. New York: Cambridge University Press, 54-85.

Thomson R (2011) Resolving Controversy in the European Union. Cambridge: Cambridge University Press.

Thomson R and Stokman F (2006) Research design: Measuring actors' positions, saliences and capabilities. In: Thomson R, Stokman F, Achen C and König T (eds) The European Union Decides. New York: Cambridge University Press, 25-53.

Thomson R, Stokman F, Achen C and König T (eds) (2006) The European Union Decides. New York: Cambridge University Press.

Tsebelis G (1994) The power of the European Parliament as a conditional agenda setter. American Political Science Review 88(1): 128-142.

Tsebelis G and Garrett G (2001) The institutional foundations of intergovernmentalism and supranationalism. International Organization 55: 357-390.

Van Den Bos J (1991) Dutch EC Policy Making: A Model-guided Approach to Coordination and Negotiation. Amsterdam: Thesis Publishers. 